J. Lake Sci. (湖泊科学), 2014, 26(6): 948-954

http: //www. jlakes.org. E-mail : jlakes@niglas.ac.cn

(C) 2014 by Journal of Lake Sciences

\title{
千岛湖流域水质变化与经济发展耦合协调性分析
}

\author{
张姗姗 ${ }^{1,2}$, 张落成 ${ }^{1 * *}$, 李 刚 $^{2}$, 李昌峰 ${ }^{2}$, 吴志旭 ${ }^{3}$ \\ (1:中国科学院南京地理与湖泊研究所湖泊与环境国家重点实验室,南京 210008) \\ (2: 南京财经大学经济学院, 南京 210046) \\ ( 3 : 淳安县环境保护监测站,杭州 311700 )
}

\begin{abstract}
摘 要: 利用主成分分析和相关分析相结合的方法, 建立水环境质量和经济发展的协调度模型, 对千岛湖流域水环境与 经济发展趋势及协调度变化趋势进行分析. 结果表明, 2000 年以来千岛湖流域水环境质量与经济发展协调状况经历了从 濒临失调向轻度失调再到趋近协调的转变过程: 以 5 年为滑动周期考察协调度的演变趋势发现, 2000-2012 年千岛湖流 域协调度大致呈 “V”型趋势, 2000-2004 年水环境质量略有下降, 经济发展缓慢, 2004-2008 年由于经济迅猛发展、水环 境质量迅速下降, 水质与经济发展处于失调状态, 经过 2008 年转折点后, 水环境质量开始改善, 2008-2012 年协调度达 最高点,处于趋近协调,开始向初级协调状态转变.
\end{abstract}

关键词: 水环境质量; 经济发展; 协调度;千岛湖流域

\section{Coordination analysis between water quality and economic development in Lake Qiandao basin}

ZHANG Shanshan ${ }^{1,2}$, ZHANG Luocheng ${ }^{1}$, LI Gang ${ }^{2}$, LI Changfeng ${ }^{2} \&$ WU Zhixu ${ }^{3}$

(1: State Key Laboratory of Lake Science and Environment, Nanjing Institute of Geography and Limnology, Chinese Academy of Sciences, Nanjing 210008, P. R. China)

(2: School of Economics, Nanjing University of Finance and Economics, Nanjing 210046, P. R. China)

(3: Chun'an Environmental Monitoring Station, Hangzhou 311700 , P. R. China)

Abstract: Based on the relationship study of water environment and economic development, this article established a coordination degree model about water environment quality and economic development combined with the concept of coordination degree. Through analysis of the variation trend of coordination degree between water environment and economic development (CDWEED) in Lake Qiandao basin, conclusions were obtained as follows. The CDWEED had undergone a transformation from inharmonious to elementary harmonious. Taking five years as a circle to study the variation of CDWEED in Lake Qiandao basin, the result indicated that the trend of CDWEED is almost in line with the "V-shaped" curve from 2000 to 2012. During 2000-2004, the water environment quality declined slightly and the economy developed slowly. During 2004-2008, the CDWEED was almost disharmonious, and water environment quality declined rapidly along with the rapid economic development. But the water environment quality began to improve after 2008 , and the coordination degree reached the highest point between 2008 and 2012 , and it was approaching the primary coordination.

Keywords: Water environment quality; economic development; coordination degree; Lake Qiandao basin

千岛湖是新安江水电站大坝建成蓄水后形成的人工湖泊,兼有发电、防洪、灌溉、旅游、养殖、航运、引用 水源及工农业用水等多项功能, 因而千岛湖水环境质量对该地区居民饮用水安全和经济发展具有重要意

* 中国科学院重点部署项目 (KZZD-EW-10-04-2)、中国科学院南京地理与湖泊研究所 “一三五” 战略发展规划项目 ( NIGLAS2012135006) 和国家自然科学基金重点项目 (41130750) 联合资助. 2013-10-16 收稿;2014-03-03 收修 改稿. 张姗姗 (1987 ), 女, 博士研究生;E-mail: shanshanzhang1126@ 163.com.

** 通信作者;E-mail:lchzhang@ niglas. ac. cn. 
义. 水环境质量演变与经济发展具有很强的耦合关系, 比如工业或者养殖业的发展会影响到湖泊水环境, 而 湖泊水污染反过来也会影响行业的发展 ${ }^{[1-2]}$. 近些年来, 国内外出现的一系列水危机事件,引起了各界的广 泛关注.

协调度理论最初由德国物理学家赫尔曼・哈肯于 1971 年提出 ${ }^{[3]}$, 即系统发生相变与否由系统控制参 量决定, 系统相变过程通过系统内部自组织来实现. 近年来,该理论被广泛用于研究环境污染与经济发展的 相互作用关系. 吴跃明等 ${ }^{[4]}$ 利用协同论的观点, 以溧阳市作为研究对象构建了环境经济协调度预测模型, 为 溧阳市环境与经济的持续发展提供了量化决策依据,李鹤等 ${ }^{[5]}$ 通过对辽宁省 1990 年以来环境和经济协调 状况进行定量评价, 提出 1990 年以来辽宁省环境和经济协调状况经历了从失调向初级协调的转变过程. 环 境经济协调度评价中最常见的方法是综合指数法 ${ }^{[6-11]}$. 国外的相关研究多见于环境与经济相互作用关系的 研究 (如环境库兹涅茨 EKC 曲线) 以及对包含资源、环境、社会、经济等多要素在内的发展的可持续性进行 定量评价 ${ }^{[12-13]}$. 目前而言, 对千岛湖流域水质变化的研究比较多, 主要包括两个方面: (1) 千岛湖水体水质 参数研究, 如叶绿素时空分布特征 ${ }^{[14-15]}$ 、营养盐时空分布特征 ${ }^{[16]} ;(2)$ 千岛湖流域水质变化特征与趋势分 析 ${ }^{[17-18]}$. 但很少有学者对千岛湖水质变化与经济发展的协调关系进行研究.

环境指标选择方面,已有研究大多采用比较宏观的环境指标,如废水、废气、固废的排放量等,对具体反 映水环境质量的各类指标 (化学需氧量、总氮、总磷、氨氮) 与经济发展关系的研究却相对较少; 另外, 经济指 标也多采用 GDP、人均 GDP 等指标, 对环境与经济结构、经济效益之间的关系则较少涉及.

\section{1 研究区概况}

千岛湖 $\left(29^{\circ} 11^{\prime} \sim 30^{\circ} 02^{\prime} \mathrm{N}, 118^{\circ} 34^{\prime} \sim 11^{\circ} 15^{\prime} \mathrm{E}\right)$ 地处浙江西部与安徽南部交界的淳安县境内, 是 1959 年 新安江水电站大坝蓄水形成的人工湖泊, 湖面纵长 $150 \mathrm{~km}$, 最宽处达 $10 \mathrm{~km}$, 平均水深 $30.44 \mathrm{~m}$, 最深处达 $100 \mathrm{~m}$, 属于典型的深水湖泊. 千岛湖流域总面积约为 $11850 \mathrm{~km}^{2}$, 杭州市境内千岛湖流域包括淳安县全境及 建德市部分区域, 本研究以淳安县全境为研究区. 千岛湖是国家级重点风景名胜区, 水库周围群山叠翠, 且 历来以水质优良而著名. 然而, 随着周边地区工业、旅游业和水产养殖业的发展, 千岛湖库区水环境质量呈 现一定的下降趋势. 1992 年, $90 \%$ 以上监测点位的年均水质属 I 类; 1998 年各监测点总氮 $(\mathrm{TN})$ 浓度严重超 标, 大部分属 IV 类, 总磷 $(\mathrm{TP})$ 浓度也在 III $\sim \mathrm{IV}$ 类之间, 透明度 $(\mathrm{SD})$ 在 II IV 类之间, 富营养化进程明显加 速. 1999 年, 淳安县建立了 “千岛湖保护专项基金”用于千岛湖环境保护工作,之后千岛湖水质有明显好转, 2000-2002 年千岛湖均能达到 II 类水质标准,部分监测点可以达到 I 类水质标准;2003-2010 年水质基本 都在 II ～III类之间,其中 2008 年水质污染较为严重, 2011-2012 年有所好转. 富营养化程度按照蔡庆华等 提出的湖泊富营养化指数 ${ }^{[19]}$ 进行衡量, 主要通过 $\mathrm{SD} 、 \mathrm{TN} 、 \mathrm{TP}$ 、高锰酸盐指数 $\left(\mathrm{COD}_{\mathrm{Mn}}\right)$ 、叶绿素 $\mathrm{a}(\mathrm{Chl}$. a $) 5$ 个 主要指标进行计算. 千岛湖 2002-2006 年富营养化程度为贫营养状态, 2007-2012 年为中营养状态. 20062012 年间, 12 个监测断面的具体水质状况见表 1 . 综合各断面来看,西南湖区茅头尖水域和东南湖区姥山出 口、三潭岛、大坝前、排岭水厂水域相对较好,街口、威坪林场、小金山等西北湖区以及百亩畈断面水质相对 较差, 且西北湖区水质明显劣于其他水域. 营养状态方面, 各监测断面均处于贫一中营养状态, 其中茅头尖一 直处于贫营养状态, 街口、小金山、威坪林场、百亩畈一直处于中营养状态. 浙皖交界街口断面千岛湖人湖水 质最差, 呈中营养状态, 主要分布在威坪镇、鸭坑乡和宋村乡等乡镇境内 ${ }^{1}$.

\section{2 数据与方法}

\section{1 数据描述}

水环境质量数据包含 $\mathrm{SD} 、 \mathrm{TP} 、 \mathrm{TN} 、 \mathrm{COD}_{\mathrm{Mn}} 、 \mathrm{COD}$ 、氨氮 $\left(\mathrm{NH}_{3}-\mathrm{N}\right) 、 \mathrm{Chl} . \mathrm{a}, 2000-2007$ 年水质数据来自淳安 县环境保护局制定的杭州市千岛湖水环境保护规划、生态文明规划等. 2008-2012 年水质数据来自淳安县 环境保护局提供的水质监测点数据. 其中, 街口、三潭岛、大坝前为国控水质监测点; 航头岛、排岭水厂、茅头 尖为市控水质监测点; 百亩畈、威坪林场、小金山、姥山出口、西园、毛竹源为县控水质监测点 (图 1). 大坝前

(1) 杭州市“十二五”千岛湖水环境保护规划. 
水质监测点位于毛竹园监测点的东侧, 因其不在淳安县境内, 故图中没有显示; 但是大坝前监测点处于出湖 口位置, 其水质与淳安县境内的经济活动具有密切联系, 在研究时也考虑在内. 经济类数据和工业废水排放 量数据来源于淳安县 (2000-2012 年) 统计年鉴,部分来源于淳安县相关统计部门.

表 112 个监测断面的水质状况 *

Tab. 1 The water quality conditions of the 12 monitoring sections

\begin{tabular}{cccccccc}
\hline 水质类别 & 2006 年 & 2007 年 & 2008 年 & 2009 年 & 2010 年 & 2011 年 & 2012 年 \\
\hline I 类 & $2 、 3 、 4 、 5 、 6 、$ & $2 、 3 、 11$ & 11 & 11 & $2 、 3 、 11$ & $2 、 3 、 4 、 5 、$ & $2 、 3 、 4 、 5 、$ \\
& $8,9 、 11$ & & & & & $6 、 7 、 11 、 12$ & $6 、 7 、 11$ \\
II 类 & $1,7 、 10$ & $1,4 、 5 、 6 、 7 、$ & $2 、 3 、 4 、 5 、 6 、$ & $2 、 3 、 4 、 5 、 6 、 7 、$ & $1,4 、 5 、 6 、 7 、$ & $1,8 、 9 、 10$ & $5 、 8 、 9 、 10 、 12$ \\
III类 & 12 & $8 、 9 、 10 、 12$ & $7 、 8 、 9 、 10 、 12$ & $8 、 9 、 10 、 12$ & $8 、 9 、 10 、 12$ & & 1 \\
\hline
\end{tabular}

* 1 : 街口, 2 : 大坝前, 3 :三潭岛, 4 : 排岭水厂, 5 : 航头岛, 6 : 茅头尖, $7:$ 西园, $8:$ 小金山,9:毛竹源, 10 : 威坪林场, 11 : 姥山出 口, 12 : 百亩畈.

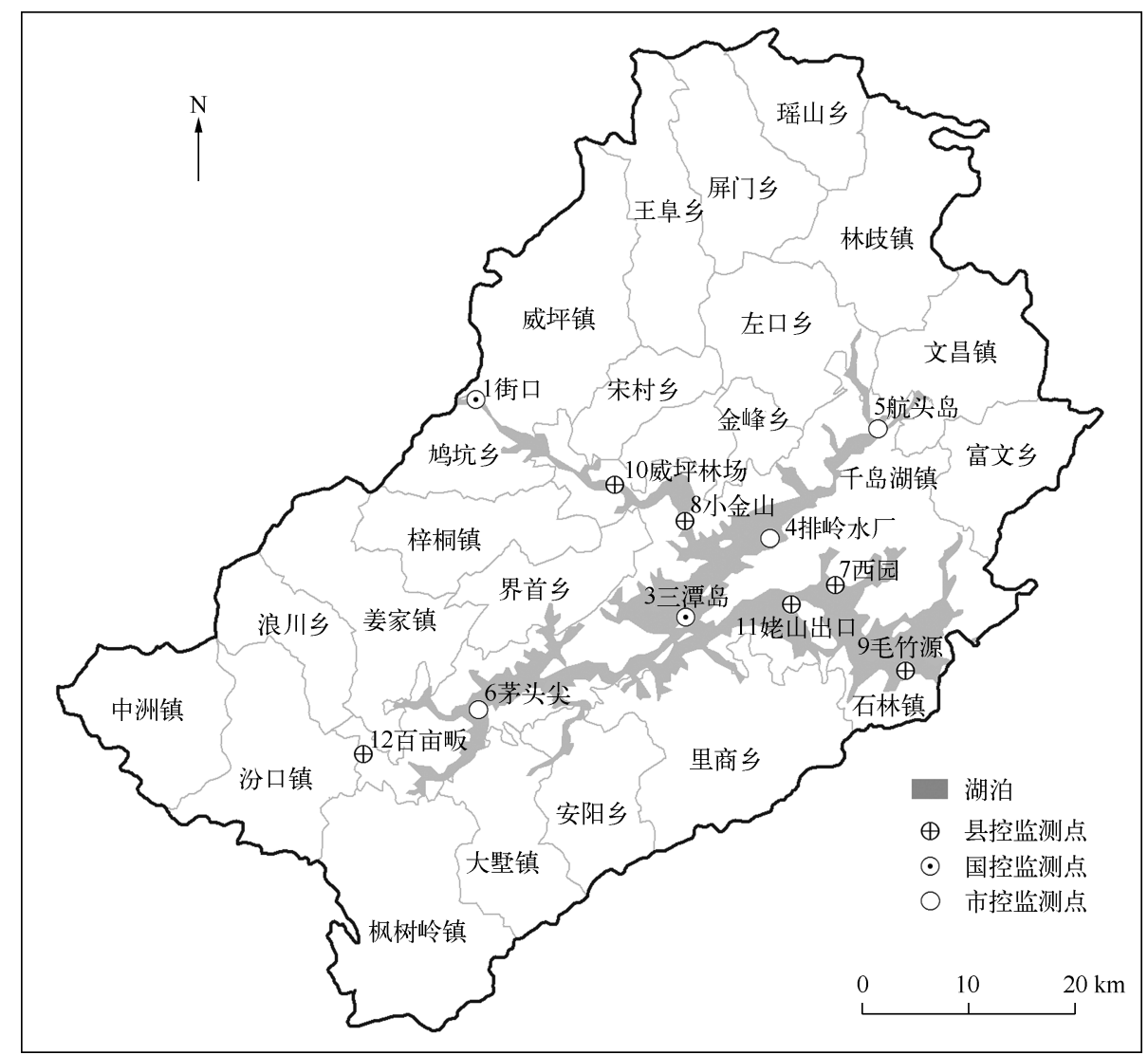

图 1 研究区与监测点分布

Fig. 1 Distribution of research area and monitoring points

\section{2 协调度模型的构建}

协调是指两种或两种以上系统或系统要素之间一种良性的相互关联, 是系统之间或系统内部要素之间 配合得当、和谐一致、良性循环的关系 ${ }^{[10]}$. 环境和经济是区域可持续空间结构中两个相互作用的子系统,两 
者之间既有正向的相互促进作用, 又有负向的相互制约作用,两者的协调发展是实现区域持续发展的必要 条件 ${ }^{[5]}$. 本文水环境和经济协调度是一个相对指标, 是对千岛湖流域 2000-2012 年时段内,水环境子系统 和经济发展子系统内部要素相互配合及两子系统间正向相互作用耦合程度的定量描述.

2.2.1 指标体系选择 千岛湖流域水环境与经济发展协调度模型包括经济发展系统和水环境系统. 经济发 展系统包含 11 个指标:GDP 总量 (亿元)、工业总产值 (亿元)、财政总收人 (万元)、固定资产投资总额 (亿 元) 主要反映千岛湖流域的经济规模和总量, 指标代码分别为 $X_{1} \sim X_{4}$; 一产比重、二产比重、三产比重主要 反映千岛湖流域的经济结构, 指标代码为 $X_{5} \sim X_{7}$; GDP 增长率、人均 GDP(元)、城镇居民恩格尔系数和社会 消费品零售总额 (亿元) 主要反映千岛湖流域的经济效益, 指标代码为 $X_{8} \sim X_{11}$. 考虑到近年来千岛湖流域水 体富营养化趋势加重, 水环境质量系统选取能够反映千岛湖水质富营养化程度的水质指标 $\mathrm{SD}(\mathrm{cm}) 、 \mathrm{COD}$ $(\mathrm{mg} / \mathrm{L}) 、 \mathrm{COD}_{\mathrm{Mn}}(\mathrm{mg} / \mathrm{L}) 、 \mathrm{NH}_{3}-\mathrm{N}(\mathrm{mg} / \mathrm{L}) 、 \mathrm{TP}(\mathrm{mg} / \mathrm{L}) 、 \mathrm{TN}(\mathrm{mg} / \mathrm{L}) 、 \mathrm{Chl} . \mathrm{a}(\mathrm{mg} / \mathrm{L})$ 和工业废水排放量 $(\mathrm{t})$ ，指标 代码分别为 $Y_{1} \sim Y_{8}$.

2.2.2 水环境质量与经济发展协调度模型的构建 由于表征水环境质量的指标 $\mathrm{COD}_{\mathrm{Mn}} 、 \mathrm{NH}_{3}-\mathrm{N} 、 \mathrm{TP} 、 \mathrm{TN}$ 、 Chl. a及工业废水排放量均为反向指标, 故需要取倒数进行正向处理, 此外, 为了排除由于量纲及数量级大小 不同造成的影响, 有必要对数据进行标准化处理, 本文采用中心化无量纲方法进行计算:

$$
x_{i j}^{*}=\left(x_{i j}-\overline{x_{j}}\right) / S_{j}
$$

式中, $x_{i j}^{*}$ 为经过标准化处理后的指标值, $x_{i j}$ 为第 $j$ 项指标的第 $i$ 个观测值, $\bar{x}_{j}, S_{j}$ 分别为第 $j$ 项指标的均值和均 方差.

本文利用主成分分析法分别对经济发展系统和水环境质量系统的综合发展状况进行评价, 该方法可以 在数据信息量损失最小的前提下,用少数几个相互独立的综合指标代替原始的多维指标. 各指标的权数确 定比较客观科学, 从而提高了评价结果的可靠性和准确性. 定义经济发展评价函数 $f(x)$ 和水环境质量评价 函数 $g(y)$, 以每个主成分方差贡献率占选取主成分的总方差贡献率的比重为权重, 乘以各个主成分的得分 构建评价函数:

$$
\begin{aligned}
& f(x)=\frac{\lambda_{1}}{\sum_{i=1}^{k} \lambda_{i}} F_{1}+\frac{\lambda_{2}}{\sum_{i=1}^{k} \lambda_{i}} F_{2}+\cdots+\frac{\lambda_{k}}{\sum_{i=1}^{k} \lambda_{i}} F_{k} \\
& g(y)=\frac{\lambda_{1}}{\sum_{i=1}^{t} \lambda_{i}} F_{1}+\frac{\lambda_{2}}{\sum_{i=1}^{t} \lambda_{i}} F_{2}+\cdots+\frac{\lambda_{t}}{\sum_{i=1}^{t} \lambda_{i}} F_{t}
\end{aligned}
$$

式中, $\lambda_{1} \cdots \lambda_{k}$ 分别是经济发展系统各个主成分的方差贡献率, $\lambda_{1} \cdots \lambda_{t}$ 分别是水环境质量系统各个主成分的方 差贡献率, $F_{1} \cdots F_{k}$ 是对经济发展指标进行主成分分析的得分, $F_{1} \cdots F_{t}$ 是对水环境质量指标进行主成分分析 的得分.

协调度是度量系统之间协调状况好坏程度的定量指标. 二者协调发展最终追求的是经济和水环境相互 促进、共同发展的状态, $f(x)$ 和 $g(y)$ 正向发展的相关性越大, 协调性就越高, 因此本文在构建两者协调度的 评价上选用相关分析方法,定义经济发展与水环境质量协调度,计算公式为:

$$
C=\frac{\sum_{i=1}^{n}\left[f(x)_{i}-\overline{f(x)}\right]\left[g(y)_{i}-\overline{g(y)}\right]}{\sqrt{\sum_{i=1}^{n}\left[f(x)_{i}-\overline{f(x)}\right]^{2}} \sqrt{\sum_{i=1}^{n}\left[g(y)_{i}-\overline{g(y)}\right]^{2}}}
$$

式中, $C$ 为协调度, $|C| \leqslant 1, f(x)_{i}$ 和 $g(y)$ 分别为第 $i$ 年的经济发展和水环境质量得分, $\overline{f(x)}$ 和 $\overline{g(y)}$ 分别表示 两个函数不同年份样本值的平均值, 式中要求 $i \geqslant 3$,一方面是由于相关分析原理对样本数的要求, 另一方面 是因为水环境状况对经济发展的影响具有滞后性,水环境状况的改变相对于经济发展而言是一个渐进的过 程, 经济发展状况容易受到偶然因素的影响而导致短期内的不规则变动, 因此水环境质量与经济发展之间 
的实际关系难以在短期内观察到. 5 年的时间既可以近似反映水环境状况的变化趋势, 又与国家和地区的经 济社会发展计划保持同步. 鉴于目前经济与水环境协调度类型划分尚无统一标准, 本文选取样本相关系数 检验的临界值作为标准进行划分. 查相关系数表可知, 样本数为 5 时, $r_{0.1} 、 r_{0.05} 、 r_{0.01}$ 的值分别为 0.805 、 $0.878 、 0.958$. 从而协调度可以划分为如表 2 所示的几种类型范围, 其中, 高级协调与严重失调的判断需要结 合图 2 .

表 2 经济与水环境协调度分类

Tab. 2 The classification of coordination degree between economic and water environment

\begin{tabular}{ccll}
\hline & \multicolumn{1}{c}{$C$ 值 } & 类型 & 特征 \\
\hline 协调类 & $0.958 \leqslant C \leqslant 1$ & 高级协调 & $f(x)$ 和 $g(y)$ 保持极强的同步增长趋势 \\
& $0.878 \leqslant C<0.958$ & 中级协调 & $f(x)$ 和 $g(y)$ 保持较强的同步增长趋势 \\
& $0.805 \leqslant C<0.878$ & 初级协调 & $f(x)$ 和 $g(y)$ 基本保持同步增长趋势 \\
调和类 & $-0.805 \leqslant C<0.805$ & 濒临失调 $($ 趋近协调 $)$ & $f(x)$ 和 $g(y)$ 相关性不明显, 处于过渡阶段 \\
不协调类 & $-1 \leqslant C<-0.805$ & 轻度失调 & $f(x)$ 上升、g(y)下降或 $f(x)$ 下降、 $g(y)$ 上升 \\
& $1 \geqslant C \geqslant 0.805$ & 严重失调 & $f(x)$ 和 $g(y)$ 呈现同步衰退趋势 \\
\hline
\end{tabular}

\section{3 结果与讨论}

\section{1 千岛湖流域水环境质量与经济发展变化趋势及协调度变化趋势分析}

3.1 .1 水环境质量与经济发展变化趋势分析 本文采用主成分和相关分析法评价 $2000-2012$ 年千岛湖流 域水环境质量与经济发展系统的关系, 运用 SAS 软件进行主成分分析, 选取特征值大于或接近 1 的主成分, 计算特征值、贡献率和累计贡献率及特征向量, 分析结果见表 3.

表 3 主成分分析结果

Tab. 3 The result of main component analysis

\begin{tabular}{|c|c|c|c|c|c|c|}
\hline 经济发展系统 & $\mathrm{F}_{1}$ & $\mathrm{~F}_{2}$ & 水环境系统 & $\mathrm{F}_{1}$ & $\mathrm{~F}_{2}$ & $\mathrm{~F}_{3}$ \\
\hline 特征值 & 7.5473 & 2.432 & 特征值 & 4.0598 & 1.7539 & 0.8654 \\
\hline 贡献率 & $68.61 \%$ & $22.11 \%$ & 贡献率 & $50.75 \%$ & $21.92 \%$ & $10.82 \%$ \\
\hline 累计贡献率 & $68.61 \%$ & $90.72 \%$ & 累计贡献率 & $50.75 \%$ & $72.67 \%$ & $83.49 \%$ \\
\hline GDP 总量 & 0.3637 & 0.0102 & SD & 0.3719 & 0.3288 & -0.5289 \\
\hline 人均 GDP & 0.3637 & 0.0115 & COD & -0.2790 & 0.3988 & 0.5818 \\
\hline 一产比重 & -0.3383 & 0.2071 & $\mathrm{COD}_{\mathrm{Mn}}$ & 0.3699 & 0.1433 & 0.0803 \\
\hline 二产比重 & 0.2952 & 0.3091 & $\mathrm{NH}_{3}-\mathrm{N}$ & 0.3525 & -0.3239 & 0.4926 \\
\hline 三产比重 & 0.0878 & -0.5619 & $\mathrm{TP}$ & -0.0316 & 0.7146 & 0.0197 \\
\hline 工业总产值 & 0.3631 & 0.0155 & $\mathrm{TN}$ & 0.3645 & 0.3025 & 0.2930 \\
\hline GDP 增长率 & -0.0194 & -0.5110 & Chl. a & 0.4256 & -0.0120 & -0.0922 \\
\hline 财政总收人 & 0.3623 & 0.0196 & 工业废水排放量 & 0.4556 & -0.0713 & 0.1946 \\
\hline 城镇居民恩格尔系数 & -0.0378 & 0.5312 & & & & \\
\hline 固定资产投资总额 & 0.3609 & 0.0088 & & & & \\
\hline 社会消费品零售总额 & 0.3620 & 0.0401 & & & & \\
\hline
\end{tabular}

经济发展系统提取了 2 个主成分, 贡献率分别为 $68.61 \%$ 和 $22.11 \%$, 累计贡献率达到 $90.72 \%$; 水环境 系统提取了 3 个主成分, 贡献率分别为 $50.75 \% 、 21.92 \%$ 和 $10.82 \%$, 累计贡献率达到 $83.49 \%$, 均能够较好 地反映原始数据的大部分信息. 利用公式 (2)、(3) 分别构建经济发展与水环境质量评价函数 $f(x)$ 和 $g(y)$, 得到两者的表达式:

$$
f(x)=0.7563 F_{1}+0.2437 F_{2}
$$




$$
g(y)=0.6078 F_{1}+0.2626 F_{2}+0.1296 F_{3}
$$

分别计算经济发展和水环境质量的主成分得 分, 代人公式(5)、(6), 对 2000-2012 年千岛湖流 域的经济发展与水环境质量进行评价. 从经济发展 系统和水环境系统各自的发展趋势来看, 水环境质 量在 2008 年经历一个大低谷, 2008 年之前整体呈 下降趋势,2008 年之后迅速上升; 经济发展发展一 直呈上升趋势. 总体来说, 2000 年以来, 千岛湖流域 水环境质量呈波动性下降趋势, 经济发展呈平稳上 升趋势 (图 2).

3.1 .2 水环境质量与经济发展协调度变化趋势分析 为了更好地反映千岛湖流域 2000 年以来水环境质 量与经济发展协调度的变化趋势, 以 5 年为周期进 行滑动, 分别求出协调度. 可以看出, 2000 年以来千 岛湖水环境质量与经济发展的协调状况经历了从 濒临失调向轻度失调再到趋近协调的 “ $\mathrm{V}$ ” 型趋势 变化. 2000-2004 年协调度为 -0.7180 , 属于濒临 失调型; 2004-2008 年协调度为 -0.9864 , 属于轻 度失调型; $2008-2012$ 年协调度为 0.7583 , 属于濒 临失调型, 接近初级协调型(图 3).

2000-2004 年的濒临失调状态, 主要归结于 上游的人湖水质. 自 2004 年以来, 经济迅猛发展, 水环境质量快速下降, 污染逐步加重, 前后连着 4 个滑动周期均处于失调状态, 其中 2004-2008 年 协调度达低谷, 属于经济优先、水环境滞后型, 特别 是 2006-2008 年, 经济发展速度和水环境质量下 降速度均为 13 年来最快的一个阶段, 致使 2008 年 成为水环境污染最严重的一年. 之后, 《中华人民共 和国水污染防治法》和《浙江省水污染防治条例》相 继出台, 水环境质量状况有所好转, 但是仍然难以恢 复到 2006 年之前的状态, 2008-2012 年协调度达

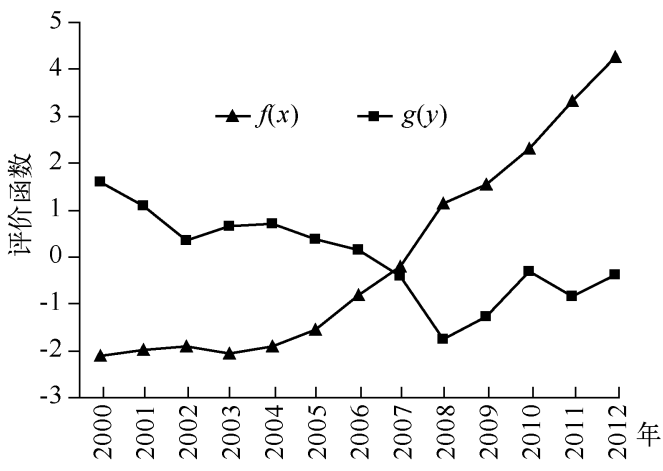

图 2 2000-2012 年水环境质量与 经济发展变化趋势

Fig. 2 The trend of water environmental quality and economic growth(2000-2012)

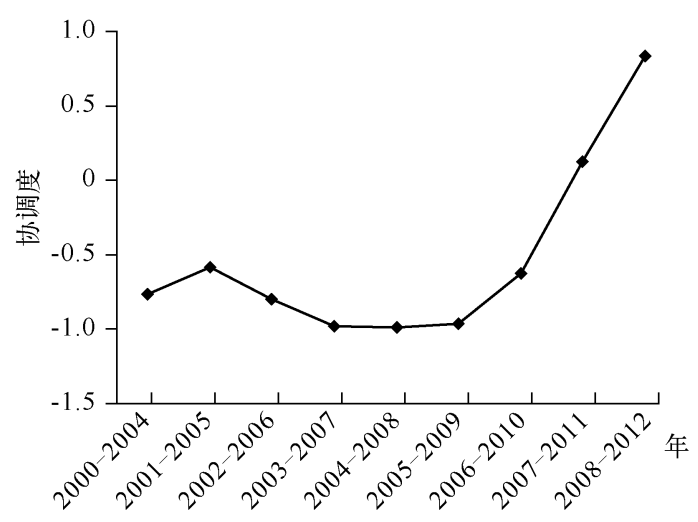

图 3 水环境质量与经济发展协调度演化趋势

Fig. 3 The trend of coordination degree between water environmental quality and economic development 最高点, 虽然呈濒临失调状态, 但已经开始向初级 协调状态迈进. 这说明 “十二五” 期间, 水环境保护更受关注, 经济继续增长, 水环境质量有所改善, 开始出现 向协调迈进的趋势, 同时也反映出水环境质量正处于调整、改善的过程,受经济发展程度影响降低.

\section{2 讨论}

选取的 8 个具体环境指标 ( $\mathrm{SD} 、 \mathrm{COD} 、 \mathrm{COD}_{\mathrm{Mn}} 、 \mathrm{NH}_{3}-\mathrm{N} 、 \mathrm{TP} 、 \mathrm{TN} 、 \mathrm{Chl}$. a 、工业废水排放量), 基本能够反映千 岛湖的水质变化特征; 11 个经济指标能反映流域经济规模、经济结构和经济效益情况. 利用这些指标研究千 岛湖流域水质演化与经济发展之间的关系具有一定的针对性和参考价值,对指导在发展千岛湖流域经济的 同时如何更好地保护环境具有一定的现实意义. 在未来的研究中, 可以考虑利用环境库兹涅茨 EKC 曲线来 分析千岛湖流域水质演化的临界点或者转折点, 并对流域水质变化与经济增长趋势进行预测分析.

\section{4 参考文献}

[ 1 ] 谢红涁, 虞孝感, 张运林. 太湖流域水环境演变与人类活动耦合关系. 长江流域资源与环境, 2001,10(5):393-400.

[2] 秦伯强,吴庆农,高俊峰等. 太湖地区的水资源与水环境问题、原因与管理. 自然资源学报,2002,17(2):221-228. 
[ 3 ] Haken H. Synergetics are cooperative phenomena governed by universal principles. Naturwissenschaften, 1980, 67 (3) : 121-128.

[4]吴跃明, 张子珩, 郎东锋. 新型环境经济协调度预测模型及应用. 南京大学学报: 自然科学版, 1996,32(3): $466-473$.

[ 5 ] 李 鹤,张平宇,刘文新. 1990 年以来辽宁省环境与经济协调度评价. 地理科学, 2007,27(4):486-492.

[6] 杨士弘.广州城市环境与经济协调发展预测及调控研究. 地理科学,1994,14(2): 136-143.

[ 7 ] 廖重斌. 环境与经济协调发展的定量评判及其分类体系一一珠江三角洲城市群为例. 热带地理, 1999,19(2): 171-177.

[8] 张晓东,池天河. 90 年代中国省级区域经济与环境协调的分析. 地理研究,2001,20(4): 507-514.

[9] 张 远, 李 芬, 郑丙辉等. 海岸带城市环境一经济系统的协调发展评价及应用一一天津市为例. 中国人口. 资 源与环境, $2005, \mathbf{1 5}(2)$ : 53-56.

[10］吴跃明,郎东锋. 环境经济系统协调度模型及其指标体系. 中国人口・资源与环境,1996,6(2):47-50.

[11］曾珍香. 可持续发展协调性分析. 系统工程理论与实践,2001,(3):18-21.

[12] Ronchi E, Federico A, Musmeci F. A system oriented integrated indicator for sustainable development in Italy. Ecological Indicators, 2002, 2(1): 197-210.

[13] Bagliani M, Bravo G, Dalmazzone S. A consumption-based approach to environmental Kuznets curves using the ecological footprint indicator. Ecological Economics, 2008, 65(3) : 650-661.

[14] 李培培, 史 文, 刘其根. 千岛湖叶绿素 a 的时空分布及其与影响因子的相关分析. 湖泊科学, 2011, 23 (4): $568-574$

[15] 王飞儿, 吕焕春, 陈英旭等. 千岛湖叶绿素 $\mathrm{a}$ 浓度动态变化及其影响因素分析. 浙江大学学报, 2001,30(1):22-26.

[16] 余员龙,任丽萍,刘其根等. 2007-2008 年千岛湖营养盐时空分布及其影响因素. 湖泊科学, 2010,22(5):684-692.

[17] 韩晓霞,朱广伟, 吴志旭等. 新安江水库 (千岛湖) 水质时空变化特征及保护策略. 湖泊科学, 2013,25(6):836-845.

[18］罗献宝,文 军,骆东奇. 千岛湖水质变化特征与趋势分析. 中国生态农业学报,2006,14(4):208-212.

[19］蔡庆华,刘建康,King L. 评价湖泊富营养化的一个综合模型. 应用生态学报,2002,13(12):1674-1678. 